\title{
WEIGHT CHARACTERIZATION OF THE TRACE INEQUALITY FOR THE GENERALIZED RIEMANN-LIOUVILLE TRANSFORM IN $L^{p(x)}$ SPACES
}

\author{
Usman Ashraf, VaKhTANG KoKILAShVILI AND ALEXANDER MesKhI
}

Abstract. Necessary and sufficient conditions on a weight governing the trace inequality for the Riemann-Liouville transform with variable parameter $R_{\alpha(x)}$ in $L^{p(x)}$ spaces are established provided that $p$ and $q$ satisfy the log-Hölder continuity condition. Weighted criteria for the compactness of $R_{\alpha(x)}$ from $L^{p(x)}$ to $L_{v}^{q(x)}$ are also derived.

Mathematics subject classification (2010): 46E30, 47B34.

Keywords and phrases: Lebesgue spaces with variable exponent, Riemann-Liouville operator, trace inequality, boundedness, compactness.

\section{REFERENCES}

[1] C. CAPONE, D. CRUZ-URibe SFO AND A. Fiorenza, The fractional maximal operator on variable $L^{p}$ spaces, Revista Mat. Iberoamericana 3(2007), No. 23, 747-770.

[2] D. Cruz-Uribe, SFO, A. Fiorenza, J. M. Martell and C. Perez, The boundedness of classical operators on variable $L^{p}$ spaces, Ann. Acad. Sci. Fenn. Math. 31(2006), 239-264.

[3] D. Cruz-Uribe, A. Fiorenza And C. J. NeugebaueR, The maximal function on variable $L^{p}$ spaces, Ann. Acad. Sci. Fenn. Math. 28(2003), No. 1, 223-238.

[4] L. DienING, Maximal function on generalized Lebesgue spaces $L^{p(\cdot)}$, Math. Inequal. Appl. 7(2004), No. 2, 245-253.

[5] L. DIENING, Riesz potentials and Sobolev embeddings on generalized Lebesgue and Sobolev spaces $L^{p(\cdot)}$ and $W^{k, p(\cdot)}$, Math. Nachr. $268(2004), 31-34$.

[6] L. DiENING, Maximal function on Musielak-Orlicz, spaces and generalized Lebesgue spaces, Bull. Sci. Math. 129 (2005), No. 8, 657-700.

[7] L. DIENING AND M. RUZICKA, Calderón-Zygmund operators on generalized Lebesgue spaces $L^{p(\cdot)}$ and problems related to fluid dynamics, J. Reine Angew. Math. 63 (2003), 197-220.

[8] L. DiEnING AND S. SAmKo, Hardy inequality in variable exponent Lebesgue spaces, Frac. Calc. Appl. Anal. 10(2007), No. 1, 1-18.

[9] D. E. Edmunds, V. KoKILASHVILI AND A. MESKHI, Bounded and compact integral operators, Kluwer Academic Publishers, Dordrecht, Boston, London, 2002.

[10] D. E. Edmunds, V. KokilashVILI AND A. MesKhI, On the boundedness and compactness of the weighted Hardy operators in $L^{p(x)}$ spaces, Georgian Math. J. 12(2005), No. 1, 27-44.

[11] D. E. Edmunds, V. KoKILAshvili AND A. MeskhI, Two-weight estimates in $L^{p(x)}$ spaces with applications to Fourier Series, Houston J. Math. (to appear).

[12] D. E. Edmunds And A. MeskHI, Potential-type operators in $L^{p(x)}$ spaces, Z. Anal. Anwend., 21(2002), 681-690.

[13] I. GenebashVILI, A. GogatishVILI, V. KoKiLASHVILI, M. KRBEC, Weight theory for integral transforms on spaces of homogeneous type, Pitman Monographs and Surveys in Pure and Applied Mathematics, Longman, Harlow, 92 (1998).

[14] L. P. Kantorovich and G. P. AKILOV, Functional analysis, Perganon, Oxford, 1982.

[15] V. M. KokILASHVILI, On Hardy's inequalities in weighted spaces, (Russian) Soobsch. Akad. Nauk Gruz. SSR 96(1979), 37-40. 
[16] V. KoKILASHVILI, On a progress in the theory of integral operators in weighted Banach Function Spaces, In "Function Spaces, Differential Operators and Nonlinear Analysis", Proceedings of the Conference held in Milovy, Bohemian-Moravian Uplands, May 28-June 2, Math. Inst. Acad. Sci. of Czech Republic, Prague, 2004.

[17] V. KoKILASHVILI AND M. KRBEC, Weighted inequalities in Lorentz and Orlicz spaces, Singapore, New Jersey, London, Hong Kong: World Scientific, 1991.

[18] V. KOKILASHVILI AND A. MESKHI, Weighted criteria for generalized fractional maximal functions and potentials in Lebesgue spaces with variable exponent, Integral Transforms Spec. Funct. 18 (2007), No. 9, 609-628.

[19] V. KOKILASHVILI AND A. MESKHI, On two-weight criteria for maximal function in $L^{p(x)}$ spaces defined on an interval, Proc. A. Razmadze Math. Inst. 145 (2007),

[20] V. KoKILASHVILI AND S. SAMKo, Maximal and fractional operators in weighted $L^{p(x)}$ spaces, Rev. Mat. Iberoamericana 20 (2004), No. 2, 493-515.

[21] V. KoKILASHVILI AND S. SAmKo, On Sobolev theorem for Riesz-type potentials in Lebesgue spaces with variable exponent, Z. Anal. Anwendungen 22 (2003), No. 4, 899-910.

[22] V. KOKILASHVILI AND S. SAMKO, The maximal operator in weighted variable spaces on metric spaces, Proc. A. Razmadze Math. Inst. 144 (2007), 137-144.

[23] V. KoKILASHVILI, N. SAMKO AND S. SAMKO, The maximal operator in variable spaces $L^{p(\cdot)}(\Omega, \rho)$ with oscillating weights, Georgian Math. J. 13 (2006), No. 1, 109-125.

[24] T. S. KOPALIANI, On some structural properties of Banach function spaces and boundedness of certain integral operators, Czechoslovak Math. J. 54(2004), No. 3, 791-805.

[25] O. KovÁCIK AND J. RÁKOSNÍK, On spaces $L^{p(x)}$ and $W^{k, p(x)}$, Czechoslovak Math. J. 41(116) (1991), No. 4, 592-618.

[26] A. Kufner, L. MaligrandA, L.-E. Persson, The Hardy inequality. About its history and some related results, Vydavatelský Series, Plzeň, 2007.

[27] A. KUfNER AND L.-E. PERSSON, Weighted inequalities of Hardy type, World Scientific Publishing Co., Inc., River Edge, NJ, 2003.

[28] M. LORENTE AND A. DE LA TORRE, Weighted inequalities for some one-sided operators, Proc. Amer. Math. Soc. 124(1996), 839-848.

[29] F. J. MARTIN-REYES AND E. SAWYER, Weighted inequalities for Riemann-Liouville fractional integrals of order one and greater, Proc. Amer. Math. Soc. 106(1989), 727-733.

[30] V. G. MAZ’YA, Sobolev spaces, Springer, Berlin, 1985.

[31] A. MESKHI, Solution of some weight problems for the Riemann-Liouville and Weyl operators, Georgian Math. J. 5(1998), No. 6, 565-574.

[32] A. MESKHI, Criteria for the boundedness and compactness of integral transforms with positive kernels, Proc. Edinb. Math. Soc., 44(2), 267-284(2001).

[33] J. MusielaK, Orlicz spaces and modular spaces, Lecture Notes in Math., 1034, Berlin, 1983.

[34] J. MusielaK AND W. ORLICZ, On modular spaces, Studia Math. 18(1959), 49-65.

[35] A. NeKVINDA, Hardy-Littlewood maximal operator on $L^{p(\cdot)\left(R^{n}\right)}$, Math. Ineq. Appl. 7 (2004), No. 2, 255-265.

[36] B. OpIC AND A. KufNer, Hardy-type inequalities, Pitman Research Notes in Math. Series 219, Longman Sci. and Tech. Harlow, 1990.

[37] W. ORLICZ, Uber konjugierte exponentenfolgen, Studia Math. 3(1931), 200-211.

[38] D. V. ProKhorov, On the boundedness of a class of integral operators, J. London Math. Soc., 61(2000), No. 2, 617-628.

[39] S. SAMKo, Convolution type operators in $L^{p(x)}$, Integral Transforms Spec. Funct. 7(1998), No. 1-2, 123-144.

[40] S. SAMKO, Convolution type operators in $L^{p(x)}\left(R^{n}\right)$, Integral Transforms Spec. Funct. 7(1998), No. 3-4, 261-284.

[41] S. SAMKO, On a progress in the theory of Lebesgue spaces with variable exponent: maximal and singular operators, Integral Transforms Spec. Funct. 16(2005), No. 5-6, 461-482.

[42] S. SAmKo, E. SHARGORODSKY AND B. VAKULOV, Weighted Sobolev theorem with variable exponent for spatial and spherical potential operators II, J. Math. Anal. Appl. 325 (2007), No. 1, 745-751.

[43] S. SAmKo And B. VAKulov, Weighted Sobolev theorem with variable exponent, J. Math. Anal. Appl. 310 (2005), 229-246.

[44] E. T. SAWYER, A characterization of a two-weight norm inequality for maximal operators, Studia Math. 75(1982), 1-11.

[45] E. T. SAWYER AND R. L. WHEEDEN, Carleson conditions for the Poisson integrals, Indiana Univ. Math. J. 40 (1991), No. 2, 639-676. 
[46] E. T. SAWYER, R. L. WHEEDEN AND S. ZHAO, Weighted norm inequalities for operators of potential type and fractional maximal functions, Potential Analysis, 5 (1996), 523-580.

[47] V. StePANOv, Two-weight estimates for the Riemann-Liouville operators, (Russian) Izv. Akad. Nauk SSSR., 54(1990), No. 3, 645-656.

[48] I. I. ShaRAPUDINOV, The topology of the space $\mathscr{L}^{p(t)}([0,1])$, (Russian) Mat. Zametki 26, No. 4, 613-632 (1979). 